\title{
A rare case of plexiform schwannoma on the foot
}

\author{
Farnaz Araghi ${ }^{1}$, mohammadreza tabary ${ }^{2}$, Kambiz Kamyab-Hesari ${ }^{3}$, Mohammad-Mehdi \\ Forouzanfar $^{4}$, and Reza Mahmoud Robati ${ }^{5}$ \\ ${ }^{1}$ Skin Research Center, Shahid Beheshti University of medical sciences \\ ${ }^{2}$ Tehran University of Medical Sciences \\ ${ }^{3}$ Razi Hospital, Tehran University of Medical Sciences \\ ${ }^{4}$ Shahid Beheshti University of Medical Sciences, Tehran, Iran \\ ${ }^{5}$ Shahid Beheshti Univ Med Sci
}

March 12, 2021

\begin{abstract}
Plexiform schwannoma mainly presented as an asymptomatic nodule located on the head, neck, or upper extremities. The presentation of this tumor on the dorsum of the foot is very rare. Herein, we report a rare case of pretty large plexiform schwannoma on the toe of a male patient.
\end{abstract}

\section{Introduction}

Plexiform schwannoma is considered a benign peripheral nerve sheath tumor that stem from the slow proliferation of Schwann cells in a meshwork configuration (1). This tumor has been observed in men and women equally and mostly presents during childhood. The size of the tumor is less than $2 \mathrm{~cm}$ in most cases (2). Possible risk factors such as a positive family history, trauma history, or neurofibromatosis type 2 may be observed in cases (2). Plexiform schwannoma is mainly presented as an asymptomatic nodule located on the head and neck region or upper extremities (3). Rarely plexiform schwannoma can present on the lower extremities particularly on the foot. According to previous reports, the presentation of this tumor on the dorsum or interdigital space of the foot seems to be the rarest manifestation (4). Herein, we describe a rare case of pretty large plexiform schwannoma on the toe in a male patient.

\section{Case presentation}

A 33 years-old male patient was referred to our dermatology clinic due to the growing soft tissue mass on his foot. Initially, the mass appeared on his second toe of the right foot 20 years ago. Recently he has noted a progressive growth in the bulk for the last 6 months. He denied any significant past medical history or drug history. He also did not mention any relevant familial history, as well.

In the physical examination, there was a non-tender erythematous nodule on the phalanx of his second right toe. The nodule was immobile and measured $3 \mathrm{~cm}$ in diameter (Figure 1). No similar lesions were observed on any other parts of his body. Accordingly, X-ray imaging confirmed that the nodule was arising with the soft tissue and no bone involvement was detected.

Punch biopsy was taken from the nodule while considering myxoid cyst, neuromas, and giant cell tumor of tendon sheath as the differential diagnoses. Microscopic examination revealed a portion of plexiform neoplasm in the dermis composed of multiple nodules of proliferated spindle cells with wavy nuclei in a fibrillary matrix. There were areas of nuclear palisading forming verocay body appearance of intervening stroma between the nodules composed of a loose meshwork of spindle cells with microcystic change and 
scattered inflammatory cells (Figure 2). In addition, immunostaining was performed for S-100 and Epithelial Membrane Antigen (EMA) and reported positive and negative, respectively (Figure3). These histopathology features were in favor of plexiform schwannoma. Finally, the patient was referred to an orthopedic surgeon in order to excise the lesion precisely.

\section{Discussion}

Herein, we reported a case of plexiform schwannoma with an unusual size that developing in an unusual location. Generally, Schwann cell tumors are categorized as neurofibromas, schwannomas, and malignant peripheral nerve sheath tumors (MPNSTs). In addition, these tumors can be considered as a manifestation of genetic diseases, such as Neurofibromatosis type 2 (NF-2), carney complex type 1, and schwannomatosis (5).

Schwannoma is considered a benign peripheral nerve sheath tumor that stems from the slow proliferation of Schwann cells (2). The plexiform schwannomas are benign tumors, which develops in a plexiform pattern; nevertheless, the malignant transformation is rarely reported (5). Clinically, this tumor often develops as a solitary subcutaneous or intradermal nodule and grows in a small size, the greatest diameter of which is mostly lower than $2 \mathrm{~cm}(6)$. Imaging particularly MRI can be helpful in diagnosis and localization of the lesion before the treatment; however, the diagnosis cannot be confirmed without histopathological studies (7).

From the histopathological view, various nodules which locate intradermally or subcutaneously consist of cellular Antoni A, in which areas with both nuclear palisading and verocay bodies are detected. In contrast to schwannomas, plexiform schwannomas develop in a plexiform configuration including various interconnecting nodules and fascicles in Antoni A areas (8). Plexiform neurofibroma could be considered as a differential diagnosis of plexiform schwannoma from a histological aspect. However, plexiform schwannomas are made of Schwann cells which can be detected via S100 protein staining (9).

\section{Conclusion}

Plexiform schwannoma is a rare benign tumors that can rarely occur on the toes. It is recommended to keep in mind this diagnosis facing bizarre large soft tissue tumors on the foot or toes. Histopathological studies are required in order to avoid misdiagnosis with other lesions. The treatment is limited to surgical treatments and complete excision is recommended to prevent recurrence (10).

\section{References}

1. Verocay J. Multiple tumors as a systemic disease of the nervous system. Memorial Publication, dedicated to Hans Chiari on occasion of his 25th year professorship jubilee Vienna, Leipzig: W Braunmueller. 1908:378415.

2. Mortazavi N, Novin K, Zerehpoosh FB, Sadatsafavi M. Plexiform Schwannoma of the Finger: A Case Report and Literature Review. Indian Dermatol Online J. 2017;8(5):355-7.

3. Ko JY, Kim JE, Kim YH, Ro YS. Cutaneous plexiform schwannomas in a patient with neurofibromatosis type 2. Ann Dermatol 2009;21(4):402-5.

4. Hao X, Levine D, Yim J, Qi C, Firestone L, Beiser I, et al. Schwannoma of foot and ankle: Seven case reports and literature review. Anticancer Res 2019;39(9):5185-94.

5. Carroll SL. Molecular mechanisms promoting the pathogenesis of Schwann cell neoplasms. Acta Neuropathologica 2012;123(3):321-48.

6. Lim HS, Jung J, Chung KY. Neurofibromatosis type 2 with multiple plexiform schwannomas. Int J Dermatol 2004;43(5):336-40.

7. Merritt IV G, Ramil M, Oxios A, Rushing C. Schwannoma of the plantarmedial aspect of the foot: A case report. Foot 2019;39:85-7. 
8. Li X-n, Cui J-l, Christopasak SP, Kumar A, Peng Z-g. Multiple plexiform schwannomas in the plantar aspect of the foot: case report and literature review. BMC Musculoskelet Disord 2014;15(1):342.

9. Parihar A, Verma S, Suri T, Agarwal A, Bansal K, Gupta R. Plexiform Schwannoma of Lumbar Region. APSP J Case Rep 2015;6(2):16.

10. Mohammed SA, Pressman MM, Schmidt B, Babu N. Case presentations and review of plexiform schwannoma in the foot. J Foot Ankle Surg 2014;53(2):179-85.

\section{Figure legends}

Figure 1: A non-tender erythematous nodule on the phalanx of the second right toe.

Figure 2 (A, B): The areas of nuclear palisading forming verocay body appearance of intervening stroma between the nodules composed of a loose meshwork of spindle cells with microcystic change and scattered inflammatory cells (A: H\&E*40, B: H\&E*100).

Figure 3 (A, B): The immunostaining reported positive was for S-100 (A*40, B*100). 


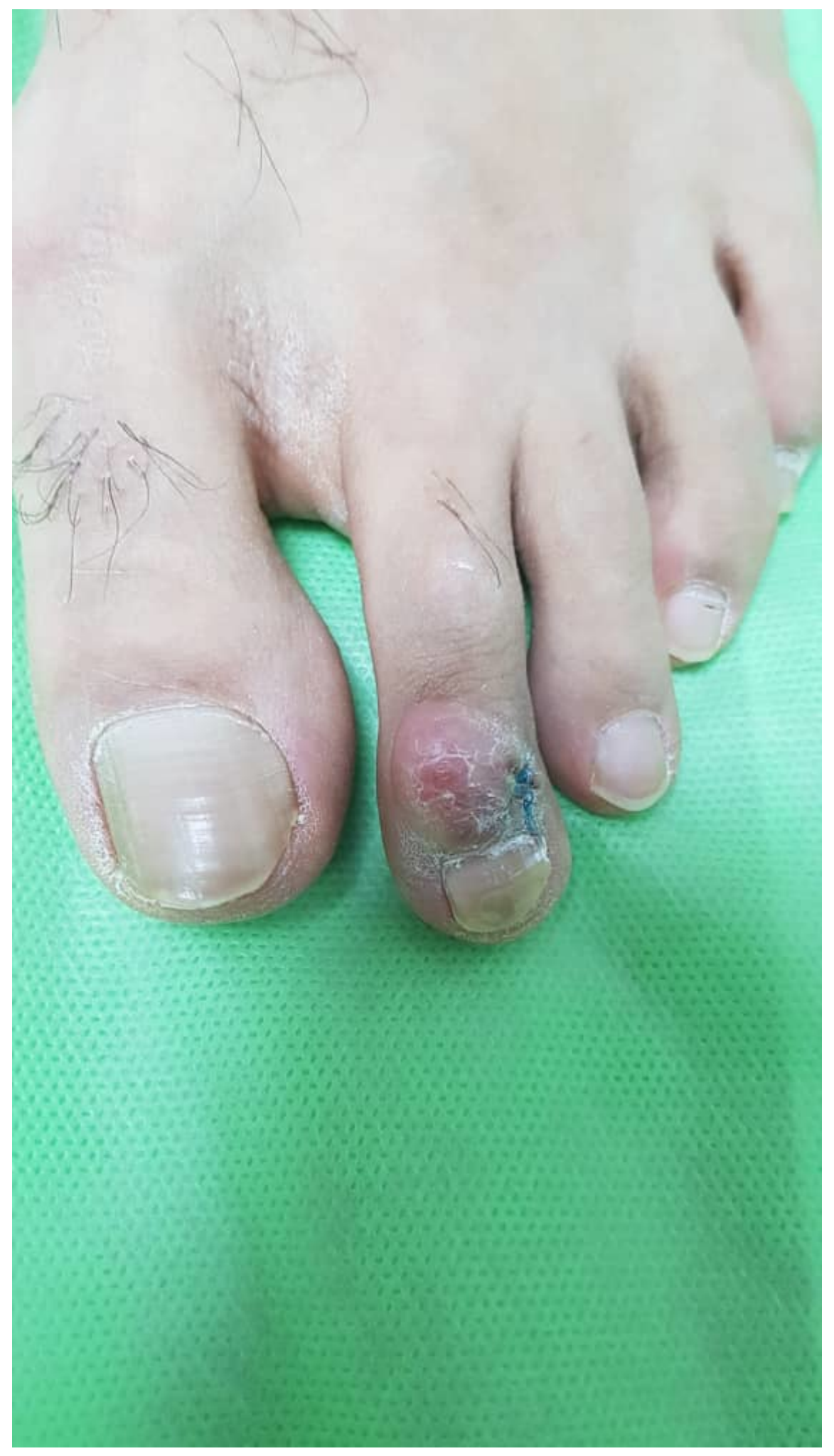



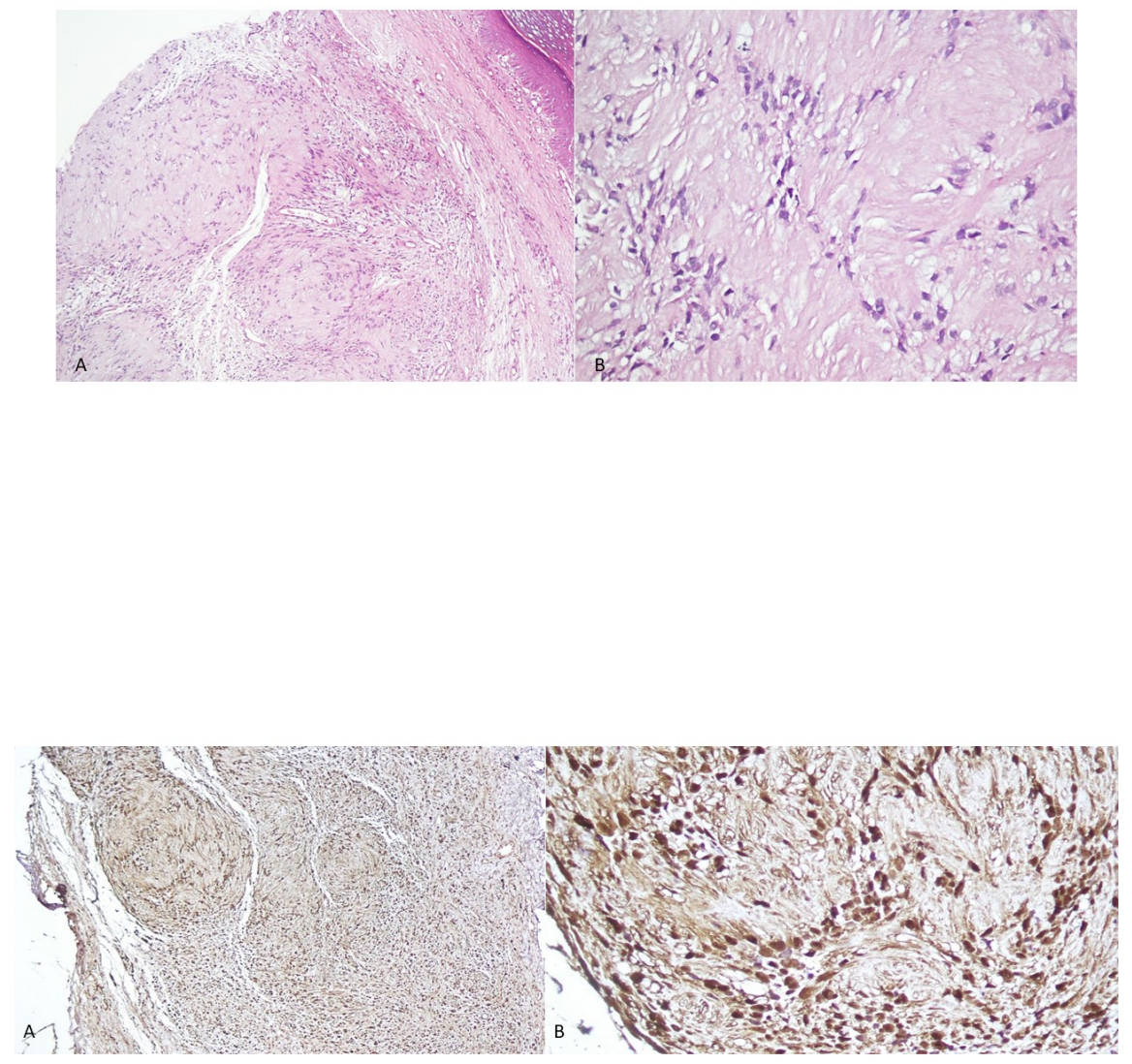